\title{
Improving the Diffusion of Lithium and Enhancing the Electrochemical Performance of Layered $\mathrm{Li}_{1.2} \mathrm{Mn}_{0.54} \mathrm{Ni}_{0.13} \mathrm{Co}_{0.13} \mathrm{O}_{2}$ Cathode by $\mathrm{YPO}_{4}$ Coating
}

\author{
Hongyu Wang ${ }^{1}$, Jing Jing ${ }^{1}$, Yi Yang ${ }^{1}$, Zuan Yang ${ }^{1}$, Fulin Yang ${ }^{1}$, Qisheng Yin ${ }^{1}$, Houyang Chen ${ }^{1}$, \\ Hongyan Yu ${ }^{1}$, Haiqing Zhan ${ }^{2}$, Xianquan Ming ${ }^{2}$, Feng Zhan ${ }^{1, *}$ \\ ${ }^{1}$ College of Resources, Environmental and Materials, Guangxi University, Nanning, Guangxi, China \\ ${ }^{2}$ South Manganse Group Limited, Nanning, Guangxi, China \\ *Corresponding author.
}

\begin{abstract}
Because of its high energy density, the manganese-rich lithium layered material is a potential cathode material for power batteries. In order to effectively strengthen the comprehensive performance of lithium-rich layered material, different amounts of $\mathrm{YPO}_{4}$ compounds were used to wet chemically coat the cathode materials. The LMNCO, 0.5$Y \mathrm{PO}_{4}, 1.0-\mathrm{YO}_{4}$ and 3.0-YPO${ }_{4}$ cathode materials are tested by XRD, SEM, TEM, XPS, constant current charge and discharge test, and EIS. Facts show that the positive electrode material coated with $\mathrm{YPO}_{4}$ has better cycle performance and rate performance. The 1.0-YPO $\mathrm{Y}_{4}$ sample material has the best performance. After 50 cycles of 0.5 $C$, its discharge capacity can still be as high as $207.4 \mathrm{mAhg}^{-1}$. The comprehensive performance of the cathode material is improved after being coated with $\mathrm{YPO}_{4}$, which is owing to the coating of $\mathrm{YPO}_{4}$. The $\mathrm{YPO}_{4}$ layer weakens the electron transfer resistance, and suppress the phase transformation of the Electrode material and the formation of the SEI film.
\end{abstract}

Keywords: Mn-based Li-rich layered material, surface modification, Rare metals, electrochemical performance

\section{Introduction}

Nowadays, the burning of fossil energy has made the global environmental pollution crisis worse. Lithium-ion batteries have been continuously studied by many researchers due to their numerous advantages, including the characteristics of high energy density per unit mass and non-damaging to the environment. Since all these strengths mentioned above, lithium-ion secondary batteries have been praised by many researchers as one of the more potential power batteries, and will be widely used in new energy vehicles of major brands[1]. While the energy density of old generation lithium battery can hardly meet the increasing demand for energy storage[2]. In efforts to replace those conventional lithium ion cathode, many research groups have studied the complex layered oxides that combined composition of $\mathrm{Li}_{2} \mathrm{MnO}_{3}$ and $\mathrm{LiMO}_{2}(\mathrm{M}=\mathrm{Ni}, \mathrm{Co}, \mathrm{Mn})$. Lithium-rich layered oxide $\mathrm{xLi}_{2} \mathrm{MnO}_{3} \cdot(1-$ $\mathrm{x}) \mathrm{LiMO}_{2}$ has attracted wide attention because of its many excellent characteristics, including higher capacity density, wider voltage window, lower cost, and so on[3].

However, studies have found that this series of cathode materials has many technical problems that need to be solved, including significant initial irreversible capacity loss, weak large-rate discharge performance, and severe attenuation of the median voltage[4]. When the charging voltage of the lithium-rich layered oxide exceeds $4.5 \mathrm{~V}$, $\mathrm{Li}_{2} \mathrm{O}$ will be separated from the $\mathrm{Li}_{2} \mathrm{MnO}_{3}$ composition. This precipitation is not reversible, which also causes the first cycle of the coulombic efficiency to drop. At the same time, Further delithium will cause the transition metal ions to diffuse and migrate spontaneously, thereby causing corresponding structural changes.

In order to solve these existing problems, coating and modifying the surface of the material Is a very useful ways to enhance the comprehensive performance of the battery. For example, $\mathrm{TiO}_{2}, \mathrm{AlPO}_{4}, \mathrm{MoO}_{3}, \mathrm{Al}_{2} \mathrm{O}_{3}$, and $\mathrm{ZnO}$ are used in the study of surface modification of cathode materials, and the research results show that these compounds

ISSN: 0010-8189

(C) CONVERTER 2021

www.converter-magazine.info 
can greatly strengthen the overall performance of cathode materials. As is known to all, rare earth elements are equipped with excellent thermodynamics stability and are easily have contact with electrode materials[5]. In this study, Li-rich layered oxide is surface treated with $\mathrm{YPO}_{4}$. To research the structure and morphology of the material, this experiment used a series of characterization methods such as XRD, SEM, TEM, SEI.

\section{Experimental}

\subsection{Synthesis of materials}

The LMNCO sample material is synthesized using acetate as the basic raw material and citric acid as the chelating agent. solving these acetic acid salts $(n(\mathrm{Li}): n(\mathrm{Mn}): \mathrm{n}(\mathrm{Co}): \mathrm{n}(\mathrm{Ni})=1.2: 0.54: 0.13: 0.13)$ in de-ionized water to make a complex solution. Well, it is worth raising excessive 5 atom\% lithium acetate $\left(\mathrm{LiAc} \cdot 2 \mathrm{H}_{2} \mathrm{O}\right)$ into this solution to make up for the quality loss of lithium in the sintering process. Weigh a certain amount of citric acid into deionized water, and then titrate it with ammonia water to maintain the $\mathrm{pH}$ is between 8-9. Mix the two solutions and then stir at $95{ }^{\circ} \mathrm{C}$ until the rotor doesn't move. The gel prepared above was dried in a drying oven, and the temperature is set to $120^{\circ} \mathrm{C}$, and the drying time is set to $12 \mathrm{~h}$. The material prepared above is put into a calciner for two calcining treatments at different temperatures.. The temperatures of the two calcinations were $450{ }^{\circ} \mathrm{C}$ and $900{ }^{\circ} \mathrm{C}$, and the calcination time was $5 \mathrm{~h}$ and $12 \mathrm{~h}$. Finally, the LMNCO sample material was prepared.

Through the following steps, different amounts of $\mathrm{YPO}_{4}$ can be coated on the positive electrode material. Stoichiometric amount of the pristine LMNCO needs to be dispersed in distilled water with strong stirring, followed by adding solving liquid of $\mathrm{Y}(\mathrm{NO})_{3} \cdot 6 \mathrm{H}_{2} \mathrm{O}$ and $\mathrm{NH}_{4} \mathrm{HPO}_{4}$ dropwise, evaporating the solvent, drying at $120^{\circ} \mathrm{C}$ for $6 \mathrm{~h}$. Finally, the obtained coating precursor was put into a heating furnace, heated to $400{ }^{\circ} \mathrm{C}$, kept for 6 hours, and then cooled with the furnace to make a coated sample. The contents of $\mathrm{YPO}_{4}$ coated on the pristine LMNCO are expected to be $0 \mathrm{wt} \%, 0.5 \mathrm{wt} \%, 1 \mathrm{wt} \%$ and $3 \mathrm{wt} \%$. They are named as LMNCO, 0.5-YPO, $1.0-\mathrm{YPO}_{4}$, $3.0-\mathrm{YPO}_{4}$, respectively.

\subsection{Characterization measurements}

The phase of the positive electrode material was detected by X-ray diffractometer (SMARTLAB3KW) with $\mathrm{Cu} \mathrm{K} \alpha$ radiation measurement. A scanning electron microscope model SU8220 was applied to characterize the microscopic morphology of the cathode material. Use the energy spectrometer (EDS) carried by the scanning electron microscope to perform elemental analysis on the samples to be tested. Use the TEM model JEOL 2010 to characterize the material. An x-ray photoelectron spectrometer with model ESCALAB 250Xl+ was used when analyzing the surface chemistry.

\subsection{Electrochemical measurements}

Three materials including cathode material, super P and PVDF are mixed and ground in a proportion of 8:1:1, and then dissolved in N-methyl-2-pyrrolidone by mass. Coating the blended slurry evenly on the coated aluminum foil on the rough surface with a machine, and place it in a vacuum drying oven, and the temperature is set to $120^{\circ} \mathrm{C}$, and the drying time is set to $12 \mathrm{~h}$. Then cutting the dried aluminum foil with a microtome into round slices with a radius of $7 \mathrm{~mm}$. The positive electrode material, lithium metal and dissepiment are assembled in a CR2032 coin cell. Assemble CR2032 coin-type battery in a glove box of SURPER. Use the electrochemical workstation model CHI760E to test the AC impedance test and electrochemical impedance spectroscopy test of the button battery. Use NEWARE battery test system to conduct electrochemical test on button battery, test voltage is $2.0 \mathrm{~V} \sim 4.8 \mathrm{~V}$, test temperature is $25^{\circ} \mathrm{C}$. 


\section{Result and Discussion}

3.1 Crystal structure analysis

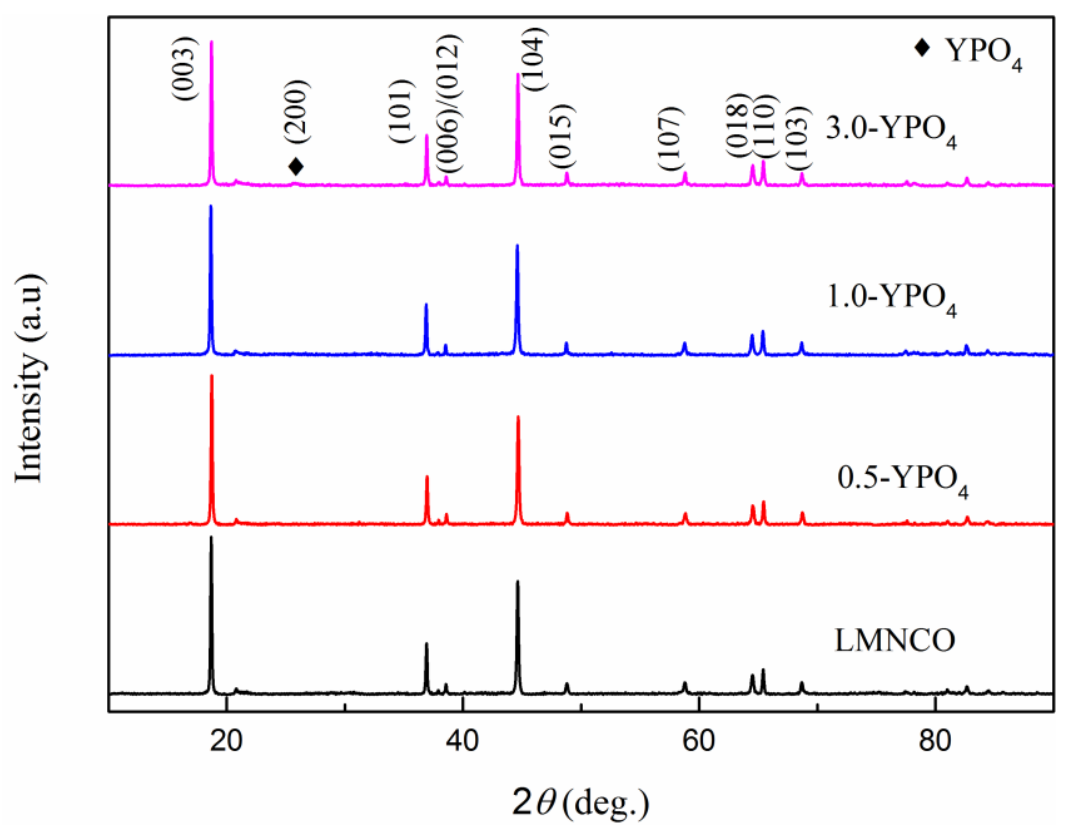

Fig. 1 XRD patterns of LMNCO, 0.5-YPO, 1.0- $\mathrm{YO}_{4}$ and 3.0-YPO $\mathrm{Y}_{4}$ cathode materials

Fig. 1 displays the XRD patterns of $\mathrm{LMNCO}, 0.5-\mathrm{YPO}_{4}, 1.0-\mathrm{YO}_{4}$ and 3.0-Y $\mathrm{YO}_{4}$ cathode materials. Fig. 1 shows that the higher intensity diffraction peaks of the four samples belong to the layered $\alpha-\mathrm{NaFeO}_{2}$ structure. This phenomenon indicates that the cathode material has a $\mathrm{LiMO}_{2}(\mathrm{M}=\mathrm{Ni}, \mathrm{Co}, \mathrm{Mn})$ structure. Careful observation of the two sets of adjacent diffraction peaks (006)/(102) and (018)/(110) shows that the two sets of diffraction peaks are clearly separated, indicating that the material has an excellent crystal structure[6]. Observing the XRD diffraction pattern, it can be found that there are several weak peaks in the $20^{\circ} \sim 25^{\circ}$ diffraction angle range. These weaker protrusions are caused by the arrangement of the three elements $\mathrm{Li}, \mathrm{Mn}$ and $\mathrm{Ni}$ in the $\mathrm{Li}_{2} \mathrm{MnO}_{3}$ composition. Observing the XRD diffraction pattern carefully, we can find that the 3.0-YPO 4 sample has a weaker, new diffraction peak, whichrepresents the (200) crystal plane of $\mathrm{YPO}_{4}$ compound.

The specific value of the intensities of the characteristic peaks of the positive electrode material (003) and (104), and the specific value of a and $\mathrm{c}$ are generally regarded as the basic feature of a positive electrode material with a layered structure. Generally, when the ratio of the intensities of the characteristic peaks of the positive electrode material (003) and (104) is less than 1.2, which means that the mixed cations in the material are serious, and when the specific value of a and $\mathrm{c}$ is less than 4.899 , it means that the material owns a very undesirable structure. Table 1 lists the lattice parameters of the four samples and the intensities of the characteristic peaks of the positive electrode material (003) and (104), calculated by JADE 6.0 software. The higher the ratio of (003) and (104) characteristic peak intensity and the ratio of the lattice parameters $\mathrm{c}$ and a means that the prepared material owns a very desirable structure. It can be found that the lattice parameters of the four sample materials before and after the coating does not change significantly. This phenomenon shows that the $\mathrm{YPO}_{4}$ coating basically has no effect on the material structure. Because the heat treatment temperature is not high enough, only 400 degrees Celsius, and it is difficult for the Y element to enter the crystals of the active substance. 
Table 1 Refined lattice parameters and ratio of characteristic peak intensities of LMNCO, 0.5-YPO $, 1.0-\mathrm{YO}_{4}, 3.0-\mathrm{YPO}_{4}$

\begin{tabular}{ccccc}
\hline Samples & $\mathrm{a} /(\AA)$ & $\mathrm{c} /(\AA)$ & $\mathrm{c} / \mathrm{a}$ & $\mathrm{I}(003) / \mathrm{I}(104)$ \\
\hline $\mathrm{LMNCO}$ & 2.8488 & 14.1826 & 4.9784 & 1.4841 \\
$0.5-\mathrm{YPO}_{4}$ & 2.8498 & 14.1714 & 4.9728 & 1.4686 \\
$1.0-\mathrm{YPO}_{4}$ & 2.8505 & 14.1885 & 4.9775 & 1.4865 \\
$3.0-\mathrm{YPO}_{4}$ & 2.8505 & 14.2155 & 4.9864 & 1.4611 \\
\hline
\end{tabular}

3.2 Micro-morphology
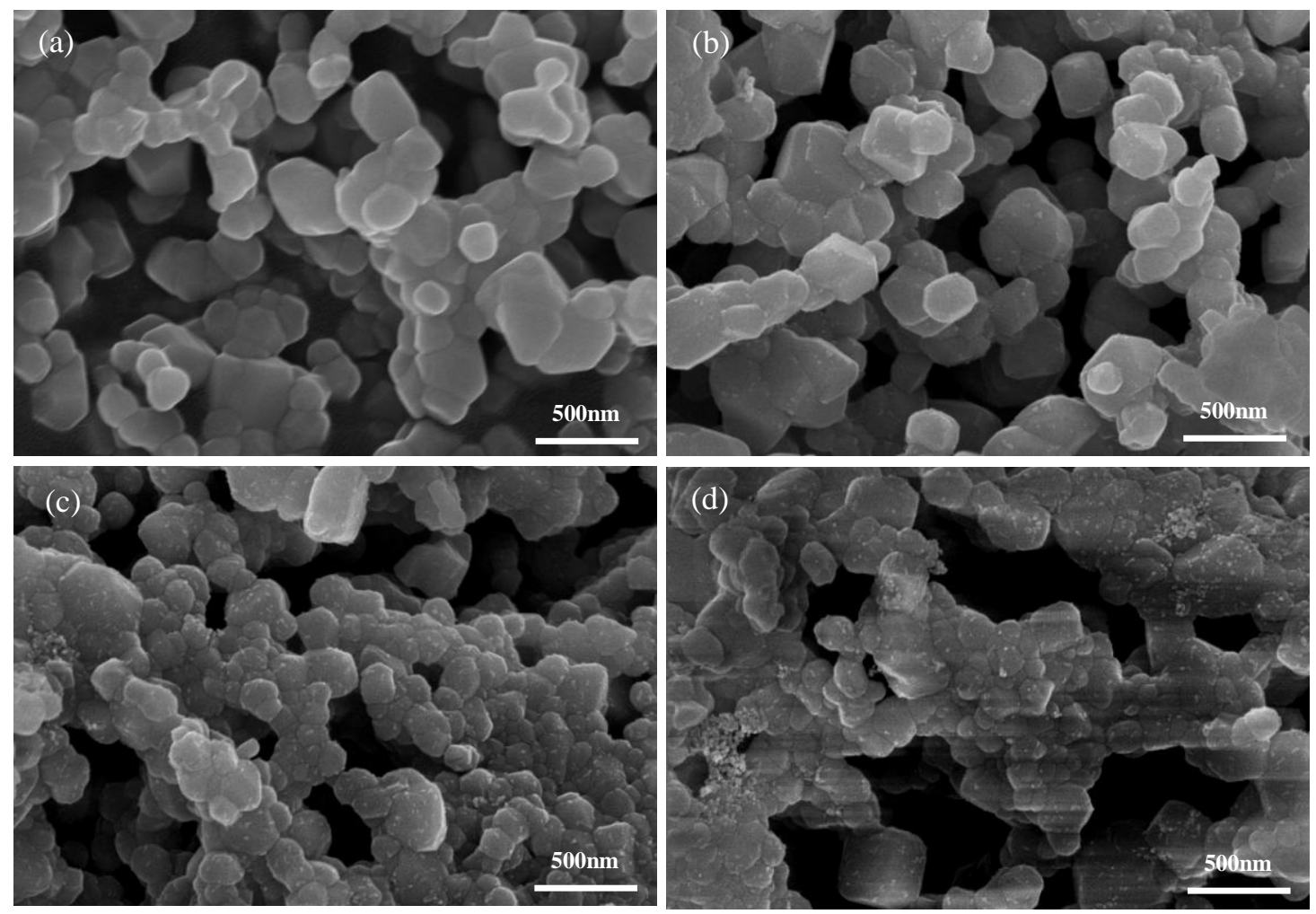

Fig. 2 Superficial morphologies of $\mathrm{LMNCO}_{(a), 0.5-\mathrm{YPO}_{4}(b), 1.0-\mathrm{YPO}_{4}(\mathrm{c}) \text { and 3.0-YPO}}$ (d) cathode materials

Fig. 2 is the microscopic morphology of the four sample materials prepared in the experiment. The particles of all samples are distributed in blocks. The surface of the LMNCO is neat and full, and the particle contour can be seen clearly. However, 0.5-YPO 4 sample is covered with a little deposit; the particle contour of the sample coated with $1.0 \mathrm{wt} \% \mathrm{YPO}_{4}$ becomes nebulous, and there are more precipitated particles attached to the outer layer of the particles; When the concentration of $\mathrm{YPO}_{4}$ compound is $3.0 \mathrm{wt} \%$, many of sedimentary deposits appear on the surface of the particles, which are connected in a local area to cover part of the particles, which means that the $\mathrm{YPO}_{4}$ package coverage may be too large.

www.converter-magazine.info 
Volume 2021, No. 5
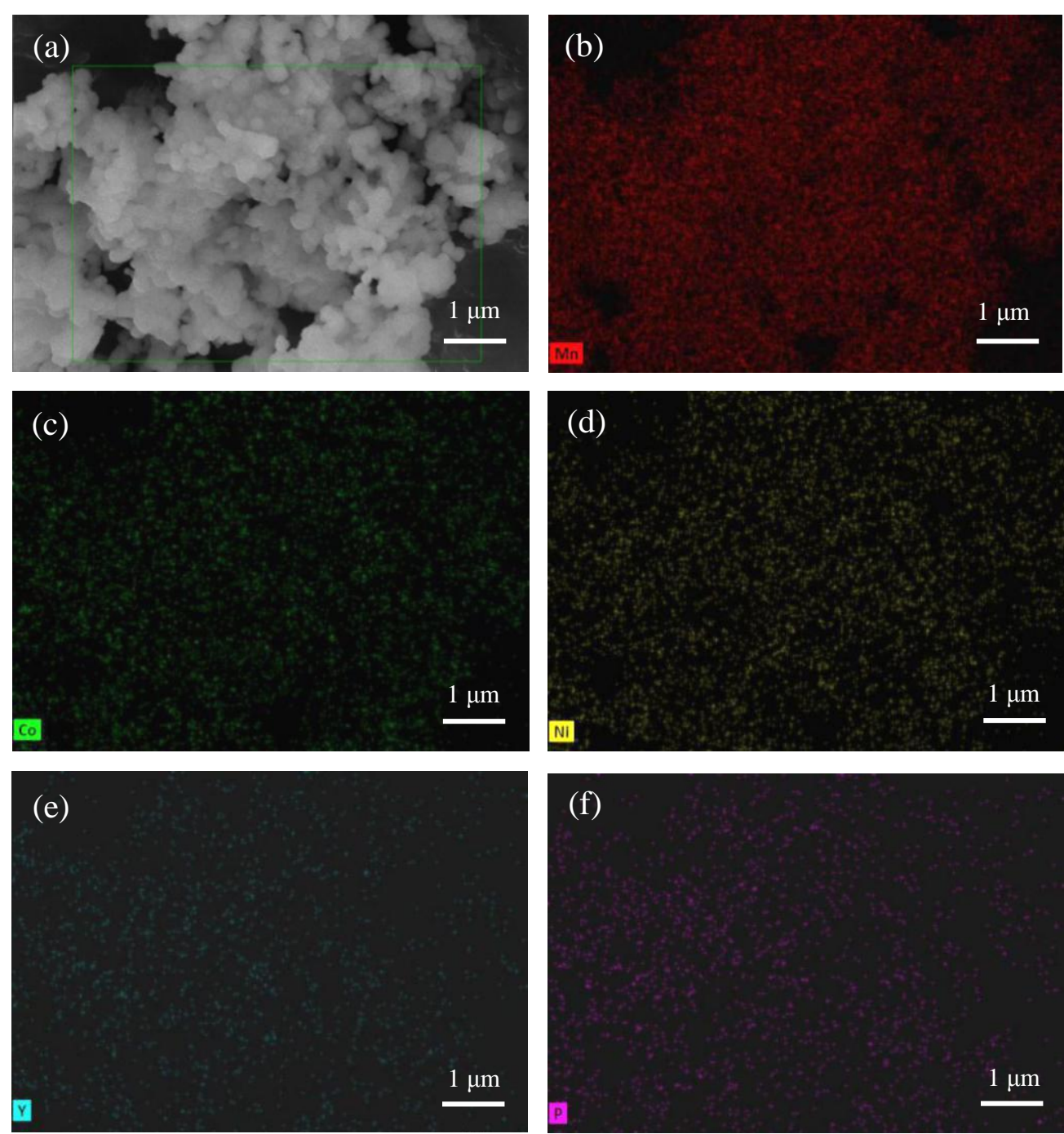

Fig. 3 Elemental mapping of the $\mathrm{Mn}(b), \mathrm{Co}(c), \mathrm{Ni}(d), \mathrm{Y}(e), P(f)$ elements of the 1.0-YPO $\mathrm{O}_{4}$ cathode material

For the purpose of getting a further study of the $\mathrm{YPO}_{4}$ coating efficiency on the material structure. SEM mapping and TEM are put to good use. Fig. 3(b-f) shows the distribution of each element in the material. The five chemical elements $\mathrm{Ni}, \mathrm{Co}, \mathrm{Mn}, \mathrm{Y}$ and $\mathrm{P}$ are evenly dispersed in the area where the particles are located, and no element enrichment is found, indicating that the $\mathrm{YPO}_{4}$ compound is evenly scattered on the cathode material. 

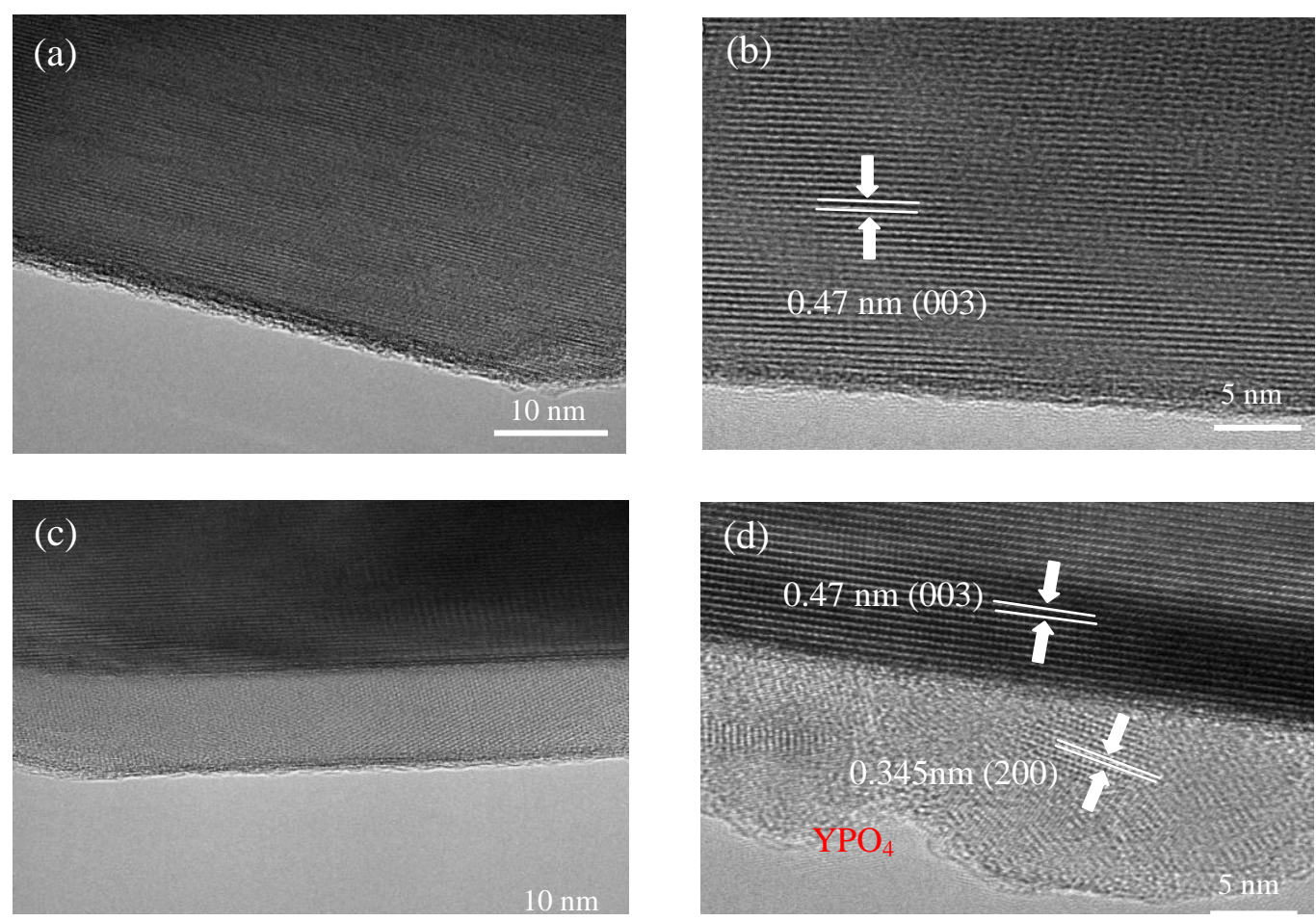

Fig. 4 TEM imagines of LMNCO $(a, b)$ and 1.0-YPO $4(c, d)$ cathode materials

Fig. 4 is TEM pictures of the LMNCO and 1.0-YPO . TEM pictures of the LMNCO shows that a continuous interference fringe is found from superficial regions to the grain edge, and the measured value of the interval between the interference fringes and fringes is $0.47 \mathrm{~nm}$, which can be index to (003) plane[7]. Comparing the LMNCO, a protective layer is coated on the $1.0-\mathrm{YPO}_{4}$ sample material. Lattice spacing of the bulk material and surface of the $1.0-\mathrm{YPO}_{4}$ are $0.47 \mathrm{~nm}$ and $0.345 \mathrm{~nm}$ respectively, which corresponds to (003) plane of the layered structure (R-3m) and (200) plane of $\mathrm{YPO}_{4}$. Observing picture Fig. 4(a), there is a thin film attached to the surface of the cathode material. It is reported that the thin film about 2-3 nm may be a $\mathrm{Li}_{2} \mathrm{CO}_{3}$ heterophase, which is commonly seen in lithium battery cathode materials. Light lithium salts are easily volatilized during the calculation stage and form $\mathrm{Li}_{2} \mathrm{CO}_{3}$ with $\mathrm{CO}_{2}$ in the air, and this miscellaneous is not a crystal structure, so it can not be shown in the XRD diffraction pattern. Substances with low conductivity will be very unfavorable to the migration and diffusion of Li-ions.

\subsection{Surface composition analysis}



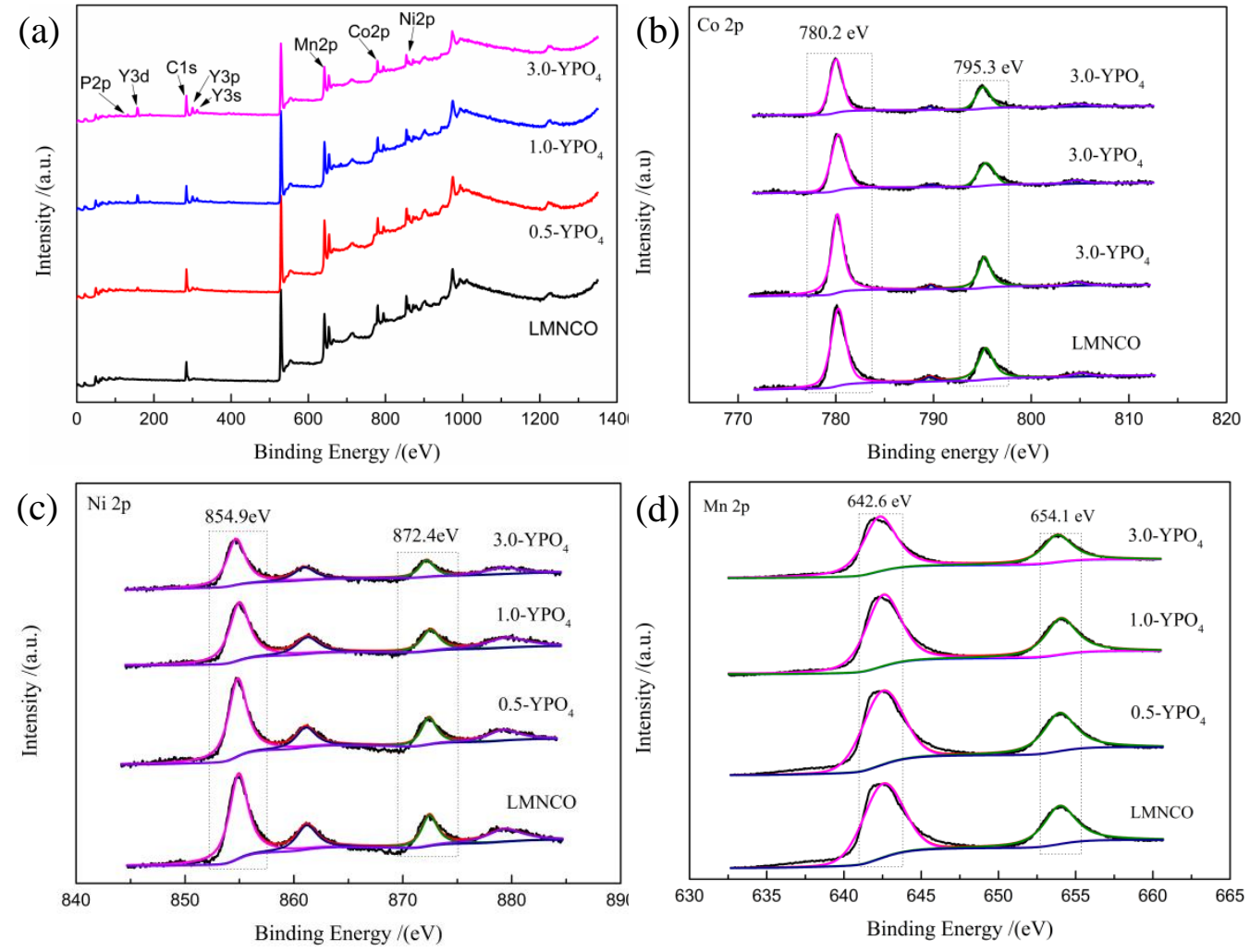

Fig. $5 \mathrm{Co} 2 \mathrm{p}(\mathrm{b}), \mathrm{Ni} 2 \mathrm{p}$ (c) and Mn 2p (d) XPS patterns of LMNCO, 0.5-YPO, 1.0-YO $\mathrm{Y}_{4}$ and 3.0-YPO $\mathrm{YPathode}_{4}$ materials

The XPS analysis data of the LMNCO and 1.0- $\mathrm{YPO}_{4}$ is a method for testing chemical states of the transition metals. Fig. 5(a) shows that $0.5-\mathrm{YPO}_{4}, 1.0-\mathrm{YPO}_{4}$ and 3.0- $\mathrm{YPO}_{4}$ have characteristic peaks of P 2p, Y 3d, Y 3p, and $\mathrm{Y} 3 \mathrm{~s}$, except for the LMNCO, and these peaks increase hand in hand with the coating amount, thus it can be confirmed that the existence of the modifier $\mathrm{YPO}_{4}$. The binding energies of the three elements $\mathrm{Ni}(2 \mathrm{p} 3 / 2)$, Co $(2 \mathrm{p} 3 / 2)$ and $\mathrm{Mn}(2 \mathrm{p} 3 / 2)$ are consistent with the binding energies of $\mathrm{Ni}^{2+}(854.5 \mathrm{eV}), \mathrm{Co}^{3+}(779.8 \mathrm{eV})$ and $\mathrm{Mn}^{4+}$ $(642.6 \mathrm{eV})[8]$. The same chemical states of $\mathrm{Ni}, \mathrm{Co}$, and $\mathrm{Mn}$ before and after coating indicate that $\mathrm{YPO}_{4}$ coating does not affect the chemical composition of the surface layer of the material. The binding energy strength of Co $2 p$, Ni 2p, Mn 2p drops while the coating amount goes higher. This is because the more coating amount of $\mathrm{YPO}_{4}$, the thicker of the $\mathrm{YPO}_{4}$ layer, and the active substance content in the XPS detection depth falls accordingly.
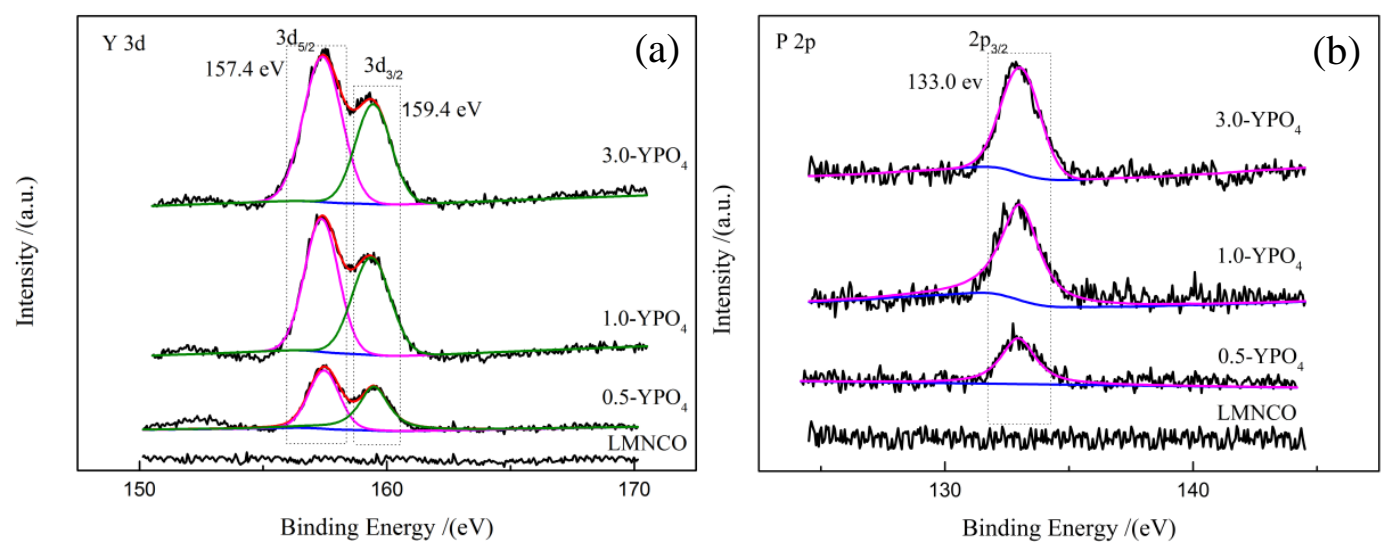

Fig. 6 Y $3 d$ (a) and P 2p (b) XPS patterns of $\quad \mathrm{LMNCO}^{-0.5-\mathrm{YPO}_{4}, 1.0-\mathrm{YO}_{4} \text { and 3.0-YPO}}{ }_{4}$ cathode materials 
It can be found by fitting that the binding energy of $\mathrm{Y}$ element is $157.5 \mathrm{eV}$ and $159.4 \mathrm{eV}$, corresponding to the binding energy of $\mathrm{Y} 3 \mathrm{~d} 5 / 2$ and $\mathrm{Y} 3 \mathrm{~d} 3 / 2$., which is in parallel with the value of $\mathrm{Y}^{3+}[5]$. The binding energy of $\mathrm{P}$ element on the material surface is about $133.4 \mathrm{eV}$, which is in parallel with the binding energy peak of $\mathrm{P}$ in $\mathrm{PO}_{4}{ }^{3-}$ [9]. Unlike peak changes of Co $2 p$, Ni $2 p$ and Mn $2 p$, the peaks of $Y 3 d$ and P $2 p$ gradually increased with the coating amount of $\mathrm{YPO}_{4}$ simultaneously. It can be seen from the above analysis that the $\mathrm{YPO}_{4}$ compound is completely coated on the original LMNCO.

\subsection{Electrochemical performance}
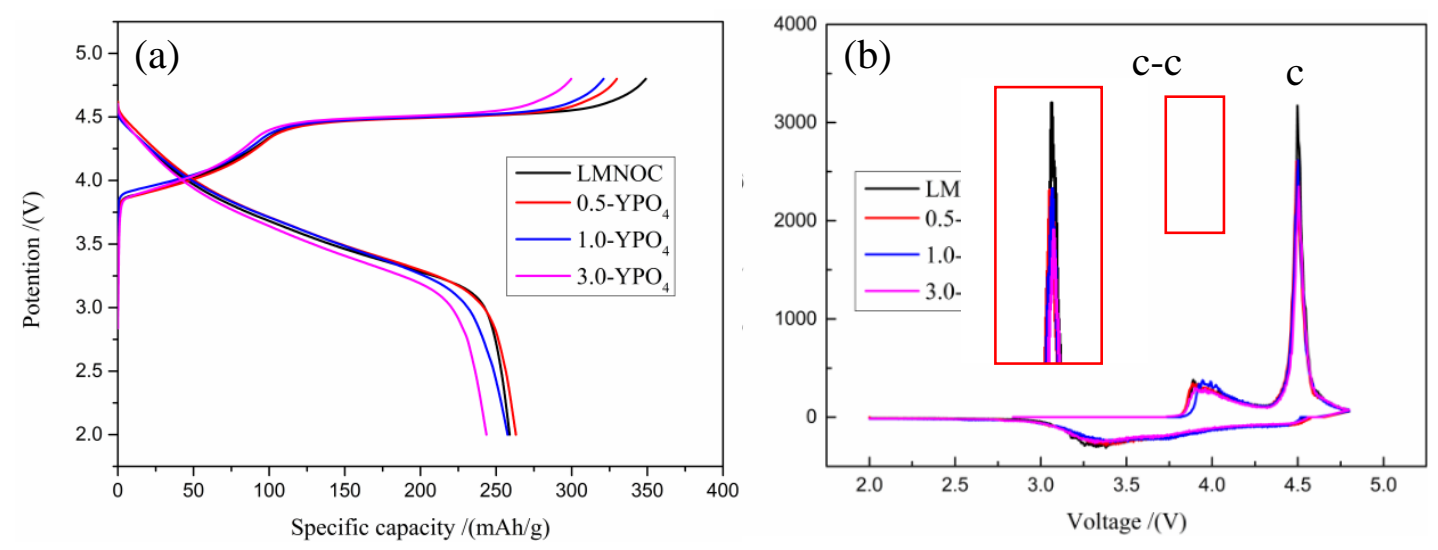

Fig. 7 The initial charge/discharge profile (a) and the corresponding initial differential capacity vs. voltage

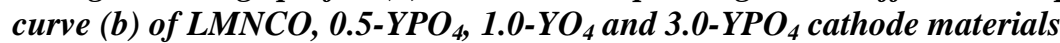

The first lap chargeldischarge curves of the four sample materials are shown in Fig. 7(a). It's clearly found that the initial charge profile shows two obvious charge areas, which is below or above $4.5 \mathrm{~V}$. When it is below $4.5 \mathrm{~V}$, the $\mathrm{LiMO}_{2}$ component is mainly involved in the charging process, and the $\mathrm{Ni}$ element and Co element undergo an oxidation reaction. When it is above $4.5 \mathrm{~V}$, the charging capacity of the material is mainly produced by the activation of the $\mathrm{Li}_{2} \mathrm{MnO}_{3}$ componen. First lap charge/discharge capacity of the LMNCO, 0.5-YPO, $1.0-\mathrm{YPO}_{4}$ and 3.0- $\mathrm{YPO}_{4}$ is $348.9 / 258.9 \mathrm{mAhg}^{-1}, 329.8 / 263.1 \mathrm{mAhg}^{-1}, 321.0 / 257.6 \mathrm{mAhg}^{-1}$ and $299.7 / 246.6 \mathrm{mAhg}^{-1}$, respectively. Fig. 7(b) shows the corresponding initial differential capacity vs. voltage curve. Two oxidation peaks can be found on the capacity differential curve. These two oxidation peaks respectively represent the recreation of $\mathrm{Li}\left[\mathrm{Ni}_{1 / 3} \mathrm{Mn}_{1 / 3} \mathrm{Co}_{1 / 3}\right]$ and $\mathrm{Li}_{2} \mathrm{MnO}_{3}$. Seen from the oxidation peak at $4.5 \mathrm{~V}$ in Figure 3-6(b), it can be found that its intensity reduces along with the climb of the $\mathrm{YPO}_{4}$ coating amount. In the meanwhile, compared with the discharge platform of the four sample materials at $4.5 \mathrm{~V}$ as shown in Fig. 7(a), it can be found that the length of the discharge platform also tends to shorten with rising coating amount, suggesting that surface treatment can restrain the activation of $\mathrm{Li}_{2} \mathrm{MnO}_{3}$ component. Table 2 lists the first lap coulombic efficiency of LMNCO, 0.5-YPO, $1.0-\mathrm{YO}_{4}$ and 3.0- $\mathrm{YPO}_{4}$ cathode materials, which are $74.2 \%, 79.8 \%, 80.2 \%$ and $81.3 \%$. The rise of the superficial $\mathrm{YPO}_{4}$ coating amount causes the enhancement of initial coulombic efficiency. It can be clearly found that the $\mathrm{YPO}_{4}$ coating can inhibit the activation process of $\mathrm{Li}_{2} \mathrm{MnO}_{3}$ component under high voltage state, reduce the precipitation of irreversible $\mathrm{Li}_{2} \mathrm{O}$ component, and advance the first lap coulombic efficiency.

Table 2 The initial charge/discharge electrochemical data of $\mathrm{LMNCO}, 0.5-\mathrm{YPO}_{4}, 1.0-\mathrm{YO}_{4}$ and 3.0-YPO 4 cathode materials

\begin{tabular}{cccc}
\hline Samples & $\begin{array}{c}\text { charge capacity } \\
\left(\mathrm{mAhg}^{-1}\right)\end{array}$ & $\begin{array}{c}\text { discharge capacity } \\
\left(\mathrm{mAhg}^{-1}\right)\end{array}$ & $\begin{array}{c}\text { Coulombic } \\
\text { efficiency \% }\end{array}$ \\
\hline LMNCO & 348.9 & 258.9 & $74.2 \%$ \\
\hline
\end{tabular}




\begin{tabular}{llll}
\hline $0.5-\mathrm{YPO}_{4}$ & 335.5 & 267.7 & $79.8 \%$ \\
$1.0-\mathrm{YPO}_{4}$ & 321.0 & 257.6 & $80.2 \%$ \\
$3.0-\mathrm{YPO}_{4}$ & 299.7 & 246.6 & $81.3 \%$ \\
\hline
\end{tabular}

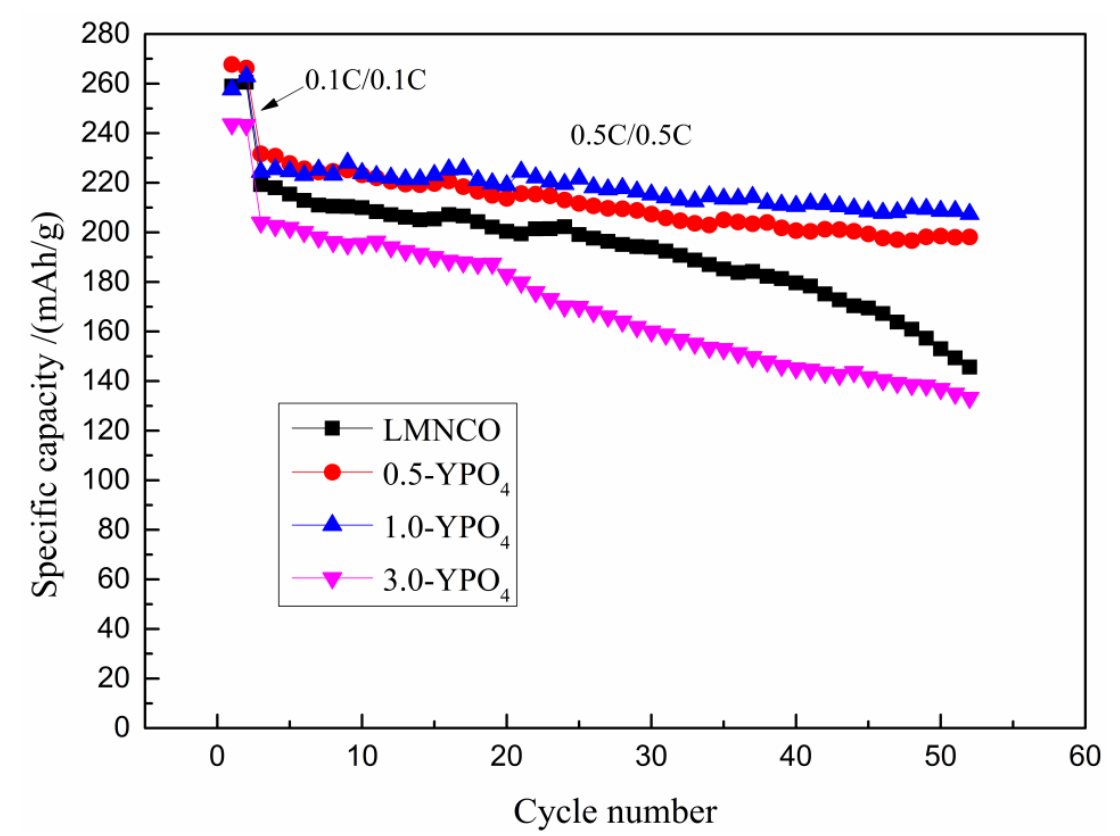

Fig. 8 Cycling performance of $\mathrm{LMNCO}^{0}$ 0.5-YPO,$~ 1.0-\mathrm{YO}_{4}$ and 3.0-YPO ${ }_{4}$ cathode materials

The cyclic performance test of samples which contains different $\mathrm{YPO}_{4}$ coating amount on the surface are conducted at $0.1 \mathrm{C}$ for the first two cycles aiming for activating materials and at $0.5 \mathrm{C}$ for the next 50 cycles in Fig. 8. The pristine $\mathrm{LMNCO}$ and $\mathrm{YPO}_{4}$ coated $\mathrm{LMNCO}$ show good cyclic performance in the first 20 cycles. However, except the 1.0- $\mathrm{YPO}_{4}$ sample, a significant capacity decline can be observed from the other samples after the first 20 cycles. For the unmodified material, the discharge capacity loss is greater after 50 cycles, from $219.3 \mathrm{mAhg}^{-1}$ to $145.6 \mathrm{mAhg}^{-1}$, and the discharge capacity loss is $66.4 \%$. After the process of $\mathrm{YPO}_{4}$ coating, the specific discharge capacities of $0.5-\mathrm{YPO}_{4}, 1.0-\mathrm{YPO}_{4}$ and 3.0-YPO ${ }_{4}$ after 50 cycles are 167.7, 207 and $133.3 \mathrm{mAhg}^{-1}$, accompanied by capacities loss of $74.7 \%, 92.3 \%, 65 \%$ respectively. Compared with the pristine $\mathrm{LMNCO}, 0.5-\mathrm{YPO}_{4}$ and $1.0-\mathrm{YPO}_{4}$ gain the upper hand in displaying better cyclic performance, especially the 1.0-YPO 4 sample. This result supports the opinions that $\mathrm{YPO}_{4}$ coated cathode material can protect the electrode material and improve the cyclic performance. On the contrary, excess amount of $\mathrm{YPO}_{4}$ can lead to thick surface coating, eliminate the reaction of lithium de-intercalation, and lower the cyclic performance. 

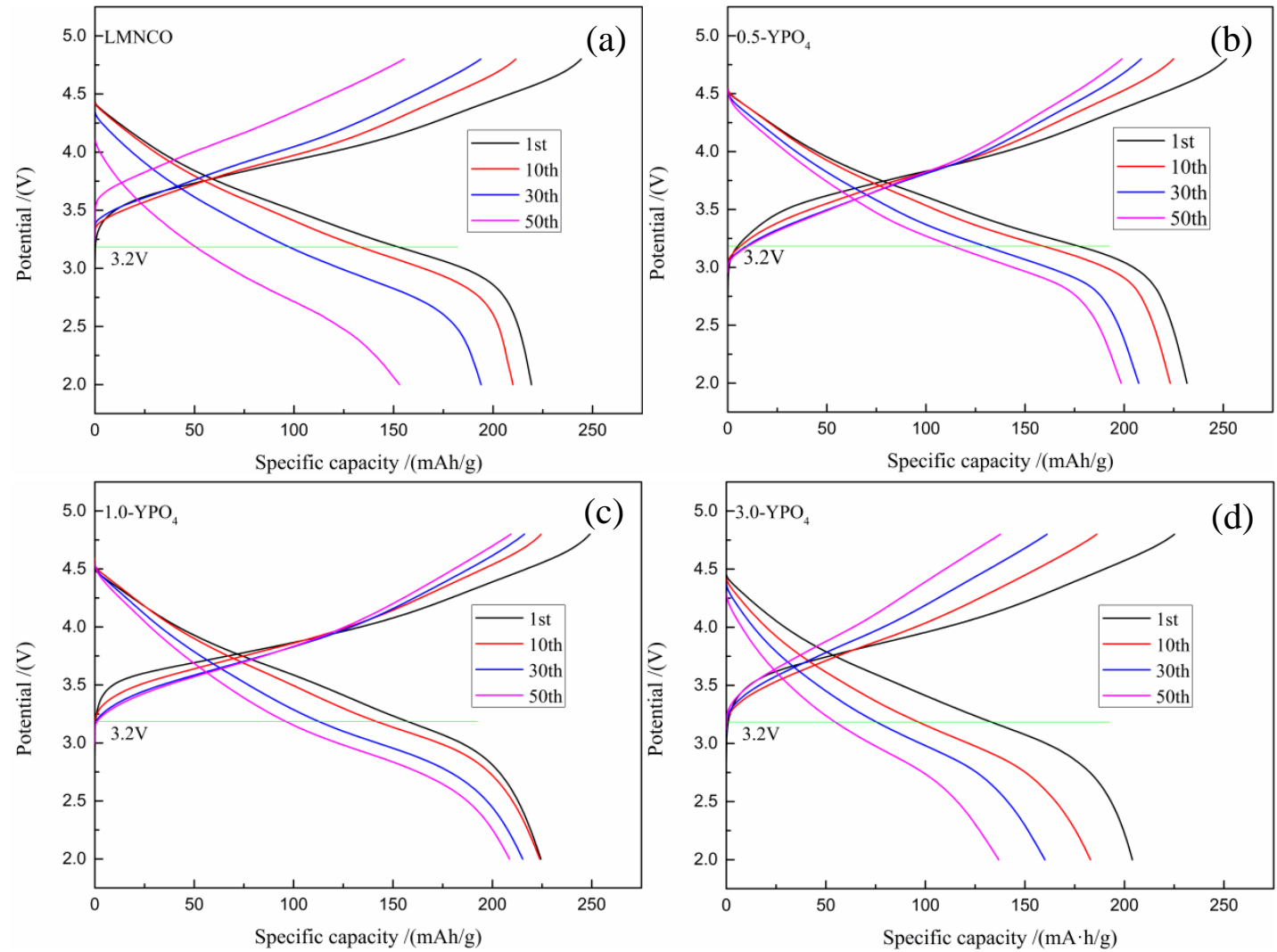

Fig. 9 Charge/discharge curves in different cycles for the LMNCO (a), 0.5-YPO4 (b), 1.0-YPO4 (c) and 3.0YPO4 (d) cathode materials

The charge/discharge curves are drawn in the $1^{\text {st }}, 10^{\text {th }}, 30^{\text {th }}$ and $50^{\text {th }}$ cycles at $0.5 \mathrm{C}$ in Fig. 9. Four sample materials experience the specific capacity loss with the electrochemical cycling. For the pristine, the discharge capacity mainly delivered between $4.8 \mathrm{~V} \sim 3.2 \mathrm{~V}$ at the first cycle, when it comes to the $50^{\text {th }}$ cycle, most of it is concentrated below $3.2 \mathrm{~V}$. As we are well-known, in the process of charge and discharge cycles, the instability of the material structure will transform the layered structure of the material, and at the same time, its redox potential will drop from $3.2 \mathrm{~V}$ to $2.8 \mathrm{~V}$. Specific discharge capacity of four samples during prolonged cycling below $3.2 \mathrm{~V}$ tends to increase, which means that the material structure will undergo irreversible changes. After the long loop is over, the proportion of the discharge capacity of the $\mathrm{LMNCO}, 0.5-\mathrm{YPO}_{4}, 1.0-\mathrm{YPO}_{4}$, and 3.0-YPO 4 between $2.0 \mathrm{~V}-3.2 \mathrm{~V}$ can reach $67.8 \%, 52.2 \%, 54.8 \%$, and $61.1 \%$, respectively (Table 2). This result proves that the superficial modification by $\mathrm{YPO}_{4}$ has the ability to suppress the phase transformation effectively. 

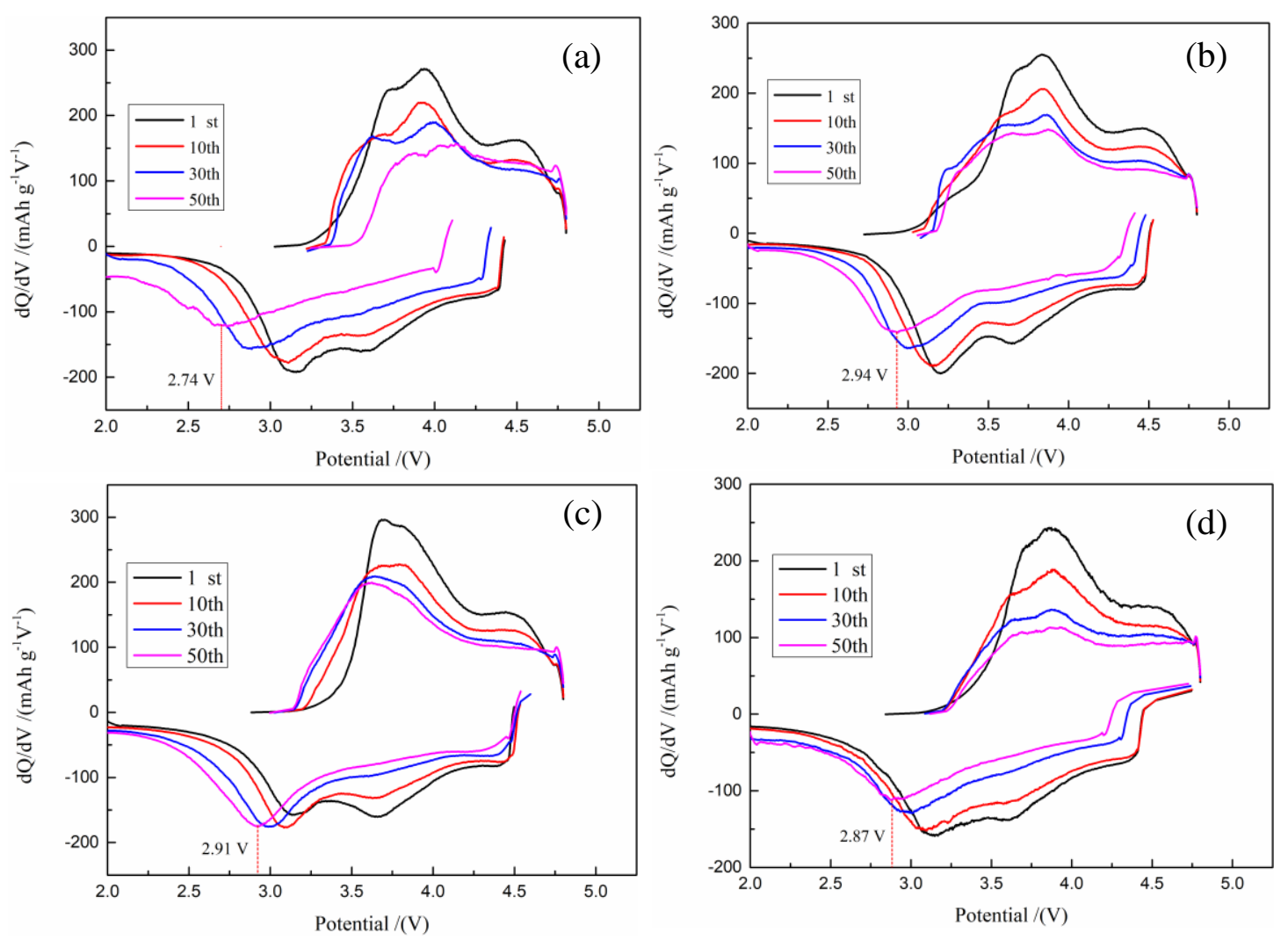

Fig.10 The corresponding initial differential capacity vs. voltage curve for the $\mathrm{LMNCO}(\mathrm{a}), 0.5-\mathrm{YPO}_{4}(\mathrm{~b}), 1.0$ $\mathrm{YPO}_{4}(\mathrm{c})$ and 3.0-YPO${ }_{4}(d)$ cathode materials

Fig. 10 shows the $d Q / d V$ curves of four samples during cycling. There are two pairs of redox peaks on the dQ/dV curves, which are related to the reduction reaction inside the material. The reduction peak at $3.76 \mathrm{~V}$ in the capacity differential curve represents the reduction process of high-valent $\mathrm{Ni}$ and $\mathrm{Co}$ ions, while another reduction peak at $3.35 \mathrm{~V}$ on the capacity differential curve represents the reduction process of $\mathrm{Mn}^{4+}$ in the $\mathrm{MnO}_{2}$ structure. For the pristine LMNCO, the reduction peak at $3.75 \mathrm{~V}$ gradually weakened, and the reduction peak gradually shifted to a low potential as the cycle continued. The shift of the reduction peak at $3.35 \mathrm{~V}$ and the weakening of the peak after the shift means that the layered structure transforms into spinel phase gradually. The shift of the redox peak at 3.35 $\mathrm{V}$ is far more lighten when it comes to $\mathrm{YPO}_{4}$ coating samples compared with the LMNCO. Compared with uncoated cathode material the reduction peak at $3.35 \mathrm{~V}$ of the $\mathrm{LMNCO}$ coated with $\mathrm{YPO}_{4}$ has undergone huge reduction, though shift still exists. In general, the LMNCO coated with $\mathrm{YPO}_{4}$ during cycling is much more stabilize than LMNCO. 


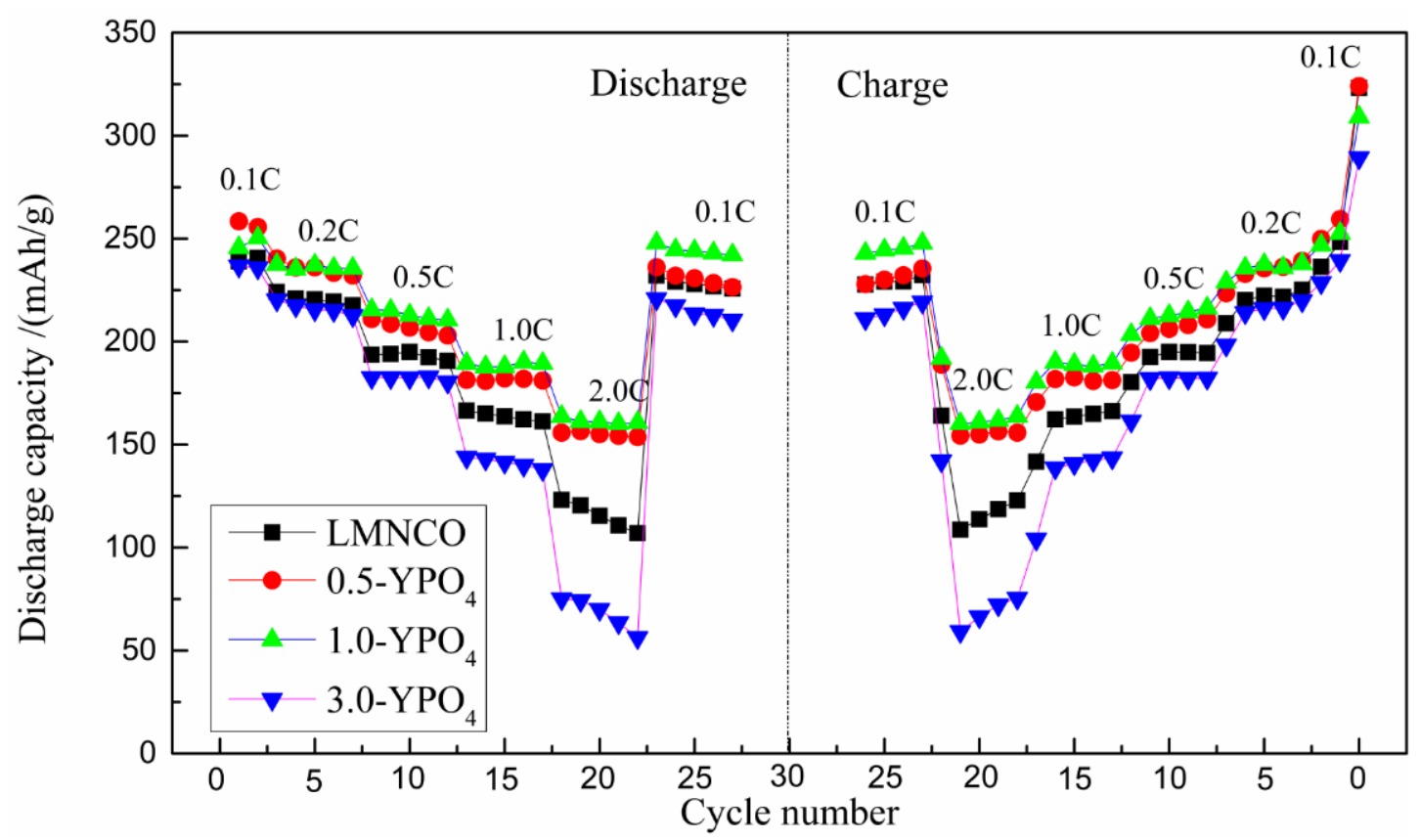

Fig. 11 Rate performance of the $\mathrm{LMNCO}, 0.5-\mathrm{YPO}_{4}, 1.0-\mathrm{YPO}_{4}$ and 3.0-YPO${ }_{4}$ cathode materials

Fig. 11 shows the rate performance of all samples. The first two loops were experimented at $0.1 \mathrm{C}$ for activation, and then 5 cycles were performed at different magnifications. The discharge capacity of the LMNCO sample at 0.2 C, $0.5 \mathrm{C}, 1 \mathrm{C}$ and $2 \mathrm{C}$ is $217.7,190.6,161.3$ and $106.9 \mathrm{mAhg}^{-1}$ respectively. Whereas the rate performance of samples with superficial modification is doing better than the pristine, especially the 1.0-YPO $\mathrm{LMNCO}_{4}$ The 1.0$\mathrm{YPO}_{4} \mathrm{LMNCO}$ releases $235.6 \mathrm{mAhg}^{-1}$ specific capacity at $0.2 \mathrm{C}$, which is higher than $217.7 \mathrm{mAhg}^{-1}$ of the pristine LMNCO. As the current density increases, the advantage of 1.0- $\mathrm{YPO}_{4} \mathrm{LMNCO}$ at the aspect of specific capacity stands out.

3.5 Electrochemical Impedance Spectroscopic (EIS) Studies

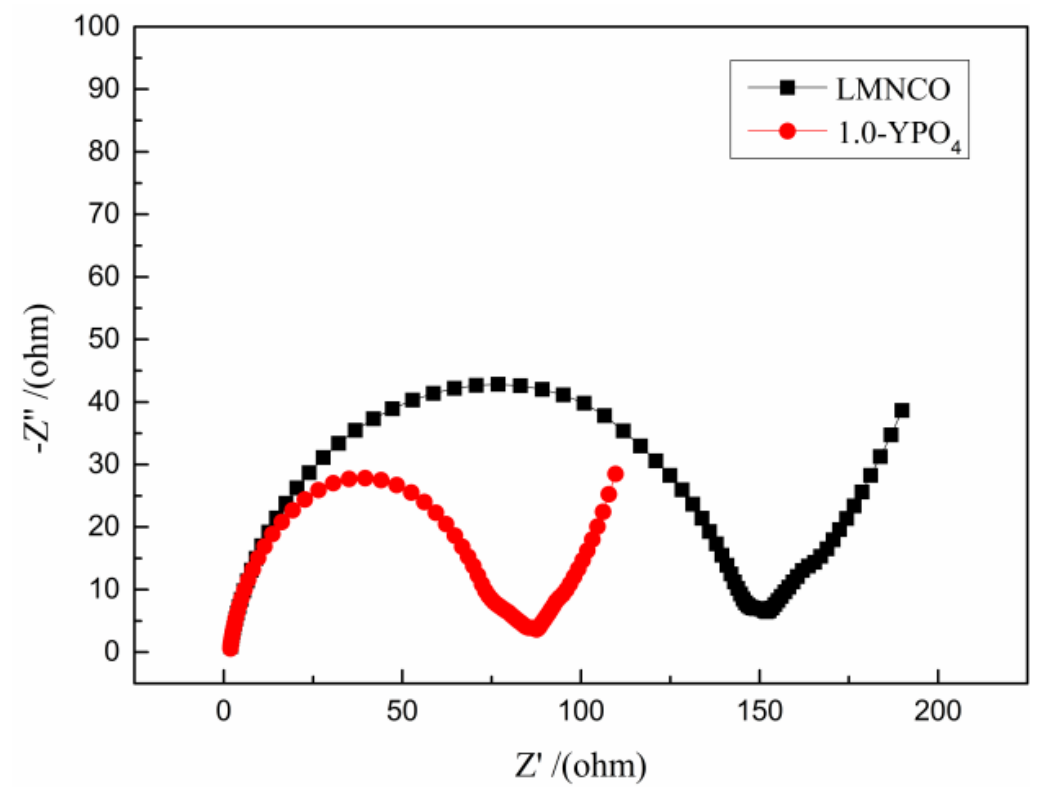

Fig. 12 EIS spectrums of samples LMNCO and 1.0-YPO4

ISSN: 0010-8189

www.converter-magazine.info 
Table 3 Fitting value of $R_{\mathrm{sf}}$ and $R_{\mathrm{ct}}$ of $\quad$ samples LMNCO and 1.0-YPO

\begin{tabular}{ccc}
\hline Samples & $R_{\mathrm{sf}} / \Omega$ & $R_{\mathrm{ct}} / \Omega$ \\
\hline LMNCO & 2.012 & 151.1 \\
$1.0-\mathrm{YPO}_{4}$ & 1.883 & 79.45 \\
\hline
\end{tabular}

AC Impedance Tester was carried out at charged potential of 4.0V. Fig. 12 is the EIS spectrums and the fitted equivalent circuits of the pristine and 1.0- $\mathrm{YPO}_{4}$. The impedance spectra of LMNCO and 1.0- $\mathrm{YPO}_{4}$ samples both contain two parts with different shapes. The first part is a semicircle pattern in the high-frequency region, and the second part is a ray in the low-frequency region. There is a small distance between the real axis of impedance and the high-frequency semicircle. This intercept represents the migration resistance of ions in the electrolyte, which is represented by the symbol $R_{\mathrm{s}}$. The intercept of the semicircle in the high-frequency region on the horizontal axis corresponds to the charge transfer impedance on the surface of the material, which is represented by the symbol $R_{\mathrm{ct}}$. The rays in the low-frequency region represent the Warburg resistance caused by the solid phase diffusion of ions in the electrode material, represented by the symbol $Z_{\mathrm{w}}[10]$.

Table 3 is the EIS data of LMNCO and 1.0-YPO 4 after fitting. From the data, the table data shows that the $R_{\mathrm{sf}}$ and $R_{\mathrm{ct}}$ impedance values of the $1.0-\mathrm{YPO}_{4}$ sample material show a significant shrinking trend, indicating that the charge transfer resistance $\left(R_{\mathrm{ct}}\right)$ that hinders the diffusion and migration of $\mathrm{Li}^{+}$is effectively reduced, so that the cathode material coated by $\mathrm{YPO}_{4}$ show better electrochemical performance.

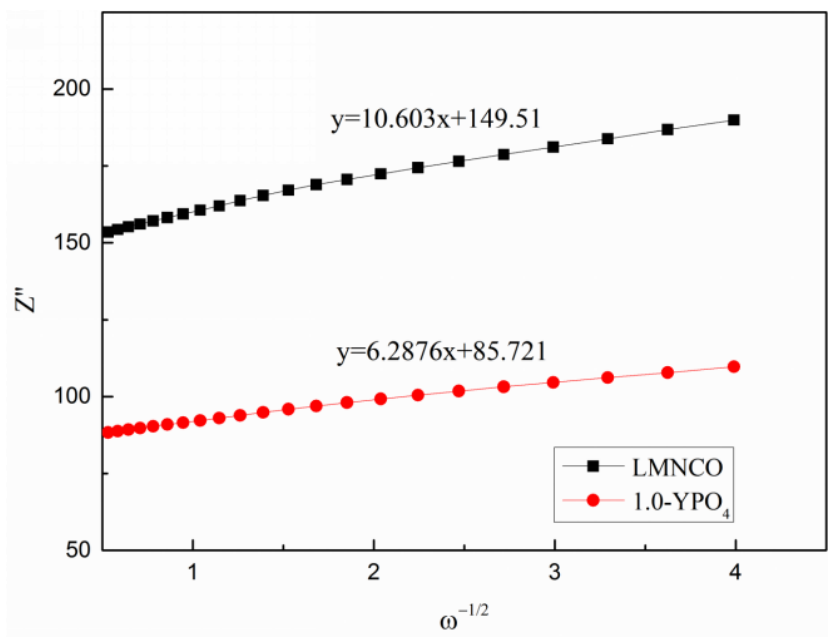

Fig. $13 Z^{\prime}$ vs $\omega^{-1 / 2}$ plots in the low-frequency region of $1^{\text {st }}$ cycle for LMNCO and 1.0-YPO

$\mathrm{Li}^{+}$diffusion coefficient of cathode materials has been calculated by the following equations, eqs 1 and 2[11].

$$
\begin{aligned}
\mathrm{D}_{\mathrm{Li}} & =\frac{0.5 \mathrm{R}^{2} \mathrm{~T}^{2}}{\mathrm{~F}^{4} \mathrm{~A}^{2} \mathrm{C}^{2} \sigma^{2}} \\
\mathrm{Z}^{\prime} & =\sigma \omega^{-0.5+\mathrm{R}^{\prime}}
\end{aligned}
$$

Fig. 13 shows $Z$ ' vs $\omega^{-1 / 2}$ plots of $1^{\text {st }}$ cycle for LMNCO and 1.0-YPO ${ }_{4}, \sigma$ represents the slope of the linear fitting graph. According to Equation (1), the larger the $\sigma$ value, the smaller the diffusion coefficient of $\mathrm{Li}^{+}\left(\mathrm{D}_{\mathrm{Li}}\right)$. It can be clearly seen by comparing the $\sigma$ value that the $\mathrm{Li}^{+}$diffusion coefficient of the LMNCO sample material is less than 1.0- $\mathrm{YPO}_{4}$. It can be seen from the above calculation results that the surface $\mathrm{YPO}_{4}$ coating can increase the $\mathrm{Li}^{+}$ 
diffusion coefficient of the positive electrode material, and accelerate the rate of insertion and extraction of lithium ions inside the body material.
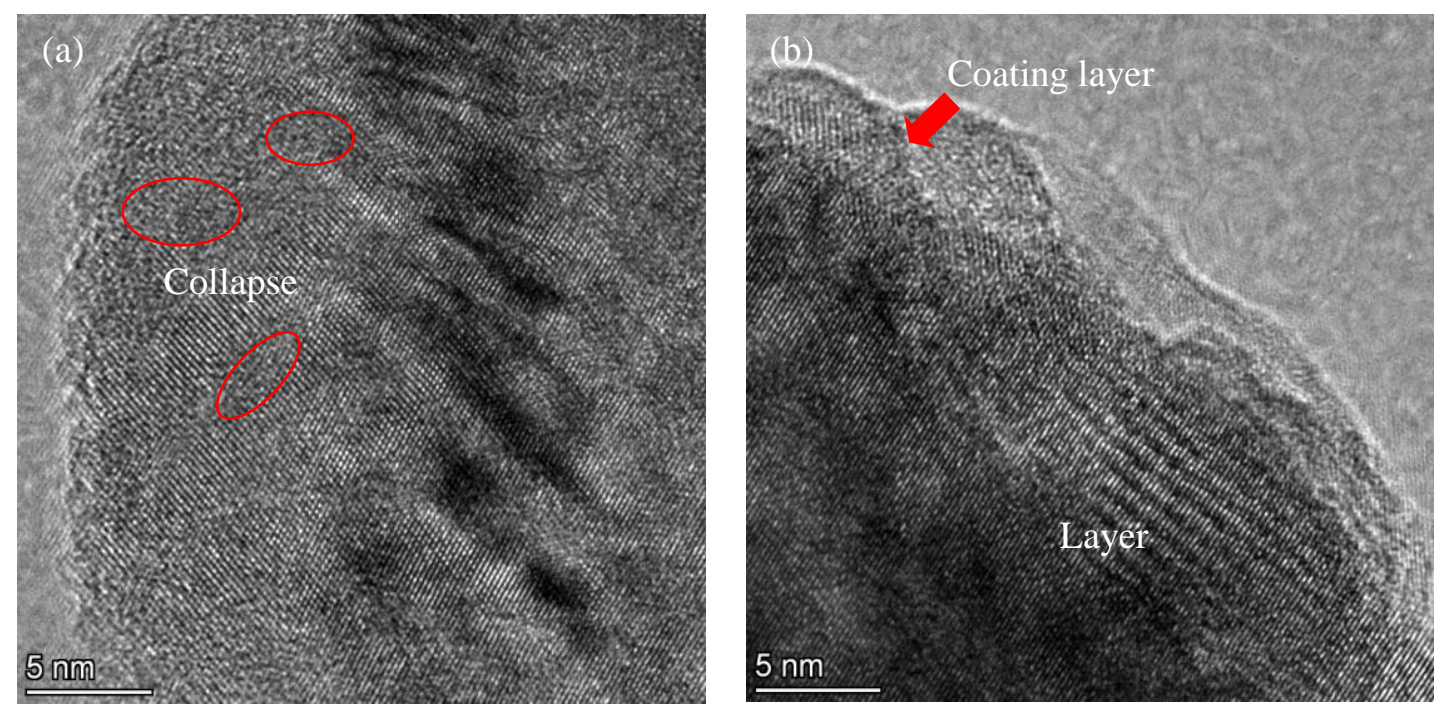

Fig. 14 TEM images of the LMNCO (a) and 1.0-YPO $\mathrm{YH}_{4}(\mathrm{~b})$ samples after cycling for 50 cycles

Fig. 14 is a TEM characterization diagram of two sample materials $\mathrm{LMNCO}$ and 1.0-Y $\mathrm{PO}_{4}$ after a long cycle test. It is quite clear shown that the structure of the LMNCO was seriously damaged, and the layered lattice structure was collapsed regionally. Different from the original sample, the 1.0-YPO 4 sample as a whole shows a clear layered structure, while the surface coating layer can also be clearly seen. This suggests that surface $\mathrm{YPO}_{4}$ coating can effectively inhibit the phase transformation, so that the material can still maintain a better layered structure after long cycle. The results are consistent with previous analysis, which indicates that surface $\mathrm{YPO}_{4}$ coating can maintain the structural stability.

\section{Conclusion}

In summary, the method of wet chemical deposition was used to successfully coat the $\mathrm{YPO}_{4}$ composite material on the lithium-rich layered oxide. TEM confirmed that after the coating treatment, a dense $\mathrm{YPO}_{4}$ film was formed on the sample. $\mathrm{YPO}_{4}$-coated samples are confirmed to have improved cycling performance and rate performance at high-rate. Comparatively, the optimal performance was observed in the $1.0 \mathrm{wt} \% \mathrm{YPO}_{4}$ modified sample. The 1.0 wt. $\% \mathrm{YPO}_{4}$ modified sample delivered $207.4 \mathrm{mAhg}^{-1}$ after 50 cycles. The $1.0 \mathrm{wt} \% \mathrm{YPO}_{4}$ modified sample also exhibited the highest rate performance of $190.1 \mathrm{mAhg}^{-1}$ at $1 \mathrm{C}$ and $163 \mathrm{mAhg}^{-1}$ at $2 \mathrm{C}$. The excellent electrochemical performance owns to the dense $\mathrm{YPO}_{4}$ protective layer, which can promote the diffusion of lithium, and protect the cathode material from damage.

\section{Acknowledgements}

This work was financially supported by Project of South Manganse Group Limited - Guangxi University Joint Research Institute of manganese resources utilization and advanced materials technology

\section{References}

[1] L. Li, Y.L. Chang, H. Xia, B.H. Song, J.R. Yang, K.S. Lee, L. Lu, "NH4F surface modification of Lirich layered cathode materials," Solid State Ionics, vol. 264, pp. 36-44, 2014. 
[2] X.F. Wen, K. Liang, L.Y. Tian, K.Y. Shi, J.S. Zheng, "Al2O3 coating on $\mathrm{Li}_{1.256} \mathrm{Ni}_{0.198} \mathrm{Co}_{0.082} \mathrm{Mn}_{0.689} \mathrm{O}_{2.25}$ with spinel-structure interface layer for superior performance lithium ion batteries," Electrochimica Acta, vol. 260, pp. 549-556, 2018.

[3] Y.F. Song, Y.Y. Liu, L.L. Cui, X.W. Miao, H.B. Zhao, J.H. Fang, "Optimized Synthetic Conditions of $0.6 \mathrm{Li}_{2} \mathrm{MnO}_{3} \cdot 0.4 \mathrm{LiNi}_{1 / 3} \mathrm{Co}_{1 / 3} \mathrm{Mn}_{1 / 3} \mathrm{O}_{2}$ Cathode Materials for LithiumBatteries via Sol-gel Method," Materials Science Forum, vol. 852, pp. 908-915, 2016.

[4] T. Tang, H.L. Zhang, "Synthesis and electrochemical performance of lithium-rich cathode material $\mathrm{Li}\left[\mathrm{Li}_{0.2} \mathrm{Ni}_{0.15} \mathrm{Mn}_{0.55} \mathrm{Co}_{0.1-\mathrm{x}} \mathrm{Al}_{\mathrm{x}}\right] \mathrm{O}_{2}$," Electrochimica Acta, vol. 191, pp. 263-269, 2016.

[5] Y. Bai, Q. Chang, Q. Yu, S. Zhao, K. Jiang, "A novel approach to improve the electrochemical performances of layered $\mathrm{LiNi}_{1 / 3} \mathrm{Co}_{1 / 3} \mathrm{Mn}_{1 / 3} \mathrm{O}_{2}$ cathode by $\mathrm{YPO}_{4}$ surface coating," Electrochimica Acta, vol. 112, pp. 414-421, 2013.

[6] W.C. West, J. Soler, B.V. Ratnakumar, "Preparation of high quality layered-layered composite $\mathrm{Li}_{2} \mathrm{MnO}_{3}-\mathrm{LiMO}_{2}(\mathrm{M}=\mathrm{Ni}, \mathrm{Mn}, \mathrm{Co}) \mathrm{Li}$-ion cathodes by a ball milling-annealing process," Journal of Power Sources, vol. 204, pp. 200-204, 2012.

[7] L. He, J. Xu, T. Han, H. Han, Y. Wang, J. Yang, J. Wang, W. Zhu, C. Zhang, Y. Zhang, "SmPO $4^{-}$ coated $\mathrm{Li}_{1.2} \mathrm{Mn}_{0.54} \mathrm{Ni}_{0.13} \mathrm{Co}_{0.13} \mathrm{O}_{2}$ as a cathode material with enhanced cycling stability for lithium ion batteries," Ceramics International, vol. 43, pp. 5267-5273, 2017.

[8] Y. Hao, F. Yang, D. Luo, J. Tian, Z. Shan, "Improved electrochemical performances of yttrium oxyfluoride-coated $\mathrm{Li}_{1.2} \mathrm{Mn}_{0.54} \mathrm{Ni}_{0.13} \mathrm{Co}_{0.13} \mathrm{O}_{2}$ for lithium ion batteries," Journal of Energy Chemistry, vol. vol. 27, pp. 1239-1246, 2018.

[9] Q.Y. Wang, J. Liu, A.V. Murugan, A. Manthiram, "High capacity double-layer surface modified $\mathrm{Li}_{1.2} \mathrm{Mn}_{0.54} \mathrm{Ni}_{0.13} \mathrm{Co}_{0.13} \mathrm{O}_{2}$ cathode with improved rate capability," Journal of Materials Chemistry, vol. 19, pp. 4965-4972, 2009.

[10] K. Zhang, L. Zhang, J. Liu, X. Wu, C. Zhou, W. Yan, C. Zhou, L. Fu, Y. Wu, "Hollow microspherical layered $\mathrm{xLi}_{2} \mathrm{MnO}_{3} \cdot(1-\mathrm{x}) \mathrm{LiNiO}_{2}(\mathrm{x}=0.3-0.7)$ as cathode material for lithium-ion batteries," Journal of Alloys \& Compounds, vol. 790, pp. 1034-1042, 2019.

[11] C. Xu, H. Yu, C. Guo, Y. Xie, N. Ren, T. Yi, G. Zhang, "Surface modification of $\mathrm{Li}_{1.2} \mathrm{Mn}_{0.54} \mathrm{Ni}_{0.13} \mathrm{Co}_{0.13} \mathrm{O}_{2}$ via an ionic conductive $\mathrm{LiV}_{3} \mathrm{O}_{8}$ as a cathode material for $\mathrm{Li}$-ion batteries," Ionics, vol. 25, pp. 4567-4576, 2019. 